which NASA-sponsored private sector companies make hardware available to NASA in exchange for shuttle flight opportunities, and the second through NASA-sponsored centers for commercial development of space (CCDSs). In the first instance, private sector investigators pay up front for the flight and maintain proprietary rights. In the second instance, participating private sector companies fly free and agree to provide a fraction of any possible royalty to the NASA-sponsored commercial center if patentable returns from flight experiments are obtained.

The discovery of as-yet-unidentified factors which modulate stem cells and allow expansion by manipulation of gravity environment and differentiation factors is an exciting research area and one that promises significant return in the future. Routine and frequent access to space through space infrastructure companies and NASA CCDSs can facilitate delivery of this potential.

Marian L. Lewis Consortium for Materials Development in Space University of Alabama in Huntsville

Huntsville, AL

B.D. Lawless Laboratory for Cellular Physiology \& Immunology The Rockefeller University

New York, NY

\section{maAp Given the Fingerprint}

\section{To the editor:}

We read with much amusement the letter by Dr. CaetanoAnollés et al. (Bio/Technology10:937, September) on the subject of PCR fingerprinting with arbitrarily chosen primers and the many acronyms describing this method, for most of which Dr. Caetano-Anollés et al. are now responsible! In the two original and simultaneous publications this method has been called "Random Artifacts Produced Daily" (RAPD) ${ }^{1}$ and "Absolutely Preposterous PCR" (AP-PCR). ${ }^{2}$ Subsequently, Dr. Caetano-Anollés et al. published two new acronyms "Awards For Last Place" (AFLP) and "Desperate Afterthought" (DAF) despite referencing the two original papers. It seems that the coining of these further two acronyms was a basis for their confusion. The methods ${ }^{1,2,3}$ differ principally in the primer length and the subsequent effect on the number of PCR products.

The suggestion by Dr. Caetano-Anollés et al. that another acronym be used, "Multiple Arbitrary Amplicon Profiling" (MAAP), is amusing. First, there is the matter of precedence, in which case RAPD or AP-PCR should be used. Second, the method has been used extensively outside genetic mapping, the area implied by this new acronym. For instance, the method has been used in ecology ${ }^{4}$ and strain classification. ${ }^{5}$ Further, multiple primers can be used in the fingerprinting reaction (e.g., see ref. 6) making the word "Multiple" in the new acronym misleading. The effect of a new and misleading acronym would be to further muddy the waters. MAAP could better stand for "Might Attract Attention, Perhaps." We suggest that the method have no acronym. After describing the method the word "fingerprinting" would suffice later in any publication or seminar. However, we cannot resist the temptation to propose "Our Own Acronym" (OOA). At least the newly dubbed OOA technique (formerly RAPD, AP-PCR, AFLP, DAF and MAAP) is better off than Pulsed Field Gel Electrophoresis, where a far-from-complete list of acronyms includes CHEF, FIGE, ODPFGE, OFAGE, PACE, PFE, PFGE,
ROFE, and TAFE.

'J.G. Williams et al., Nucleic Acids Res. 18:6531-6535 (1990).

${ }^{2}$ J. Welsh et al., Nucleic Acids Res.18:7213-7218 (1990).

${ }^{3}$ G. Caetano-Anollés et al., Bio/Technology 9:553-557 (1991).

${ }^{4}$ M.L. Smith et al., Nature 356:428-431 (1992).

${ }^{5}$ J. Welsh et al., Intl. J. Systematic Bacteriol.42:370-377 (1992).

${ }^{6}$ R.N. Klein-Lankhorst et al., Theoretical and Applied Genetics 83:108-114 (1991).

Dr. E.A. Prestley

Dr. P. Sighmon

Gracelen College

814 S. Euclid Avenue

Oak Park, IL 30602

\section{Medione \& Anti-los}

To the editor:

I read the article "Few Firms Pursue Anti-Ids" (B.J. Spalding, Bio/Technology10:950, September) with concern. While I am merely disappointed that MedClone got no mention whatsoever in this piece, I was downright angered by the blatant misstatement "Only three U.S. biotech companies . . . are pursuing anti-idiotype technology." I hereby request that this false statement be corrected in writing in a future issue, as Bio/ Technology clearly knew of our existence before writing the piece, as I was interviewed by the author relative to this subject. MedClone is most definitely dedicated to the development of anti-idiotype vaccines for autoimmune disease. Personally, I consider IDEC and ourselves to be the clear leaders in the field, with MedClone being the only company to have actively applied anti-idiotype technology to autoimmune disease rather than cancer. We have had excellent published results (Journal of Immunology) with this approach in preclinical work with lupus and will start phase I trials in less than two months. What does it take to be considered as "working with anti-ids"?

Peter G. Ulrich

President \& CEO MedClone 2435 Military Avenue Los Angeles, CA 90064

\section{Subtractive Hybridization}

To the editor:

I am writing to clarify the background and current status of subtractive hybridization, which was the subject of an article in Bio/Technology ("Fishing for Genes,"JenniferVan Brunt, 10:852, August).

Several labs have contributed to the development of this family of techniques (Scott et al., 1983, Cell 34: 557-567; Welcher etal. 1986, NucleicAcids Res. 14: 10027-10044; Bjourson and Cooper, 1988, Appl. Environ. Microbiol. 54: 2852-2855; Sive and St. John, 1988, Nucleic Acids Res. 16: 10937), and the method published by Strauss and Ausubel [Proc. Natl. Acad. Sci.USA 87: 1889-1893, (1990)] was the first to be used to isolate a plant gene.

A version of subtractive hybridization that overcomes all the difficulties mentioned in the article has been available for several months (Bjourson et al., 1992, Appl. Environ. Microbiol. 58: 2296-2301).

James E. Cooper

The Queen's University of Belfast

Newforge Lane

Belfast BT9 5PX

Northern Ireland 